\title{
EL TRABAJO DE HACER ARQUITECTURA*
}

\section{EDUARDO BUTTICE}

\section{EL MARCO HISTORICO DEL TRABAJO}

El modelo cultural que construyó la modernidad europea influyó notablemente en la producción arquitectónica de los últimos 100 años en la Argentina.

El testimonio físico-simbólico más elocuente lo encontramos en las ciudades de hoy, que contienen el amplio repertorio de formas y tipos edilicios construidos a través del tiempo, que nos pertenecen y muestran el lenguaje de lo moderno que aún consumimos.

\section{MAS ALLA DE LAS FORMAS - LA CULTURA}

Este paradigma que proporcionó también a esta parte del planeta el progreso social y democrático, - amenaza ahora- debido a su expansión sin fronteras, conducir a la humanidad hacia un futuro carente de paz.

Con la globalización de los órdenes económicos del hemisferio Norte basados en la utilización intensiva del capital y los recursos, se llega hasta los límites sociales y ecológicos del crecimiento.
La República Argentina concluyó hacia 1880 , su primera etapa, de organización nacional, hacia los años 30 , se quintuplicaba la población, la oligarquía liberal, se encaminaba hacia su engrandecimiento material, la fluida movilidad social producida por este fenómeno, no impedía que gran parte de esa población sufriera duras condiciones de vida. "El granero del mundo, tendía vías férreas, administraba moneda fuerte y desde el pródigo preámbulo de su Constitución, atraía la presencia inquieta de muchedumbres de inmigrantes". (1)

La formación universitaria incorporó los nuevos contenidos de un importante cambio estructural en la enseñanza, como lo fue la Reforma Universitaria del 18.

Los veteranos «no artistas» se apoyaron para su práctica en una incipiente mirada racionalista a favor del funcionalismo arquitectónico, cuyo

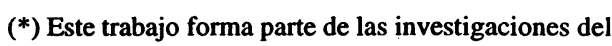
autor vinculadas con el tema: Municipio y comunidad, desarrollada en la Cátedra de Sociología Urbana de la Facultad de Arquitectura y Urbanismo de la U.N.NE.

(1) Ciria, A. y Sanguinetti, H. La Reforma Universitaria. Biblioteca Política Argentina. No. 38 y 39. Buenos Aires. Centro Editor de América Latina. 1983. 
comienzo se adjudica al «internacional style» -corriente europea iniciada en la década del 20.

"En la década del veinte, - - escribe Molina y Vedia - 'se creó el Internacional Style' para inventar y crear formas que simbolizaran a un nuevo mundo, en el que tanto la tecnología como la industria, debían enfrentarse con problemas enteramente nuevos, también nuevos para la cultura y para la sociedad en su conjunto, un mundo nuevo que debía encarar y resolver tareas específicas y recorrer caminos que llevaran de los problemas de la cantidad a los problemas de la calidad y de lo extensivo o lo superficial a lo intensivo o profundo de las cosas". (2)

Más tarde los arquitectos, fueron incorporando otros flujos de la modernidad que fueron revolventes y evolutivos con ajustes progresivos atados a los requerimientos de una nueva era, la industrial, originados en las más importantes ciudades (Londres, Berlín, Barcelona, Milán, París, New York, etc.) que funcionaron como centros de irradiación cultural progresista, a partir del proceso de acumulación capitalista.

Los colegas, podrán recordar que nuestra formación ideológica-cultural receptó la luz de los mensajes de las ideas filosóficas y simbólicas de los maestros como Mies Van Der Rohe, Le Corbusier, Gropius, Wright, del Stijl, de la Schinkel Schule, del CI-

(2) Molina y Vedia, Mario. Problemas y estrategias de diseño arquitectónico. Buenos Aires. fichas $\mathrm{N}^{\circ} 28$. Ediciones Nueva Visión. 1973.
AM, etc. ; y que esta formación nos dio una identidad, lo que permitió nuestra inserción ética y moral en la sociedad donde nos ha tocado actuar, con especial dedicación, no exenta de errores, aciertos, renunciamientos y méritos.

\section{Sospechamos...}

Que la actitud de los arquitectos modernos europeos, adheridos al funcionalismo/racionalismo, que constituyeron luego las línéas centrales operadas en la práctica profesional periférica, estuvo -mucho másdialécticamente en favor de su propia existencia como especialidad, que en favor de la adopción ligera de nuevas formas no exentas de simbolismo, emoción y estética, por cuanto su práctica, funcional, a nuevos clientes, siguió acompañando a las demandas propias del desarrollo de una burguesía industrial.

Que mientras las diferencias en los desarrollos relativos en una y otra parte del mundo no justificarían en el mismo sentido, la aplicación local de esos símbolos mediante la utilización del mismo alfabeto.

Que mientras este desarrollo industrial en lo local no se producía todavía, se importaban las formas, y con ellas venían las técnicas, las máquinas, herramientas y equipos, los materiales y aún los componentes, determinantes del resultado visible de la practica gráfica profesional, como si fuera esta practica gráfica la tarea específica del arquitecto lográndose, 
mediante el manejo simbólico, solo un espejismo de la realidad del progreso en lo local.

Que así fue como una buena cantidad de discursos fundamentaron, la importación de ideas, actividades, tipos constructivos, formas definidas por sus líneas, direccionales, escalas, tamaños, relaciones dimensionales, colores, valores, texturas, materiales, componentes, etc. que constituyeron el alfabeto de la expresión gráfica y las bases técnicas de nuestros diseñadores. (Ver cuadro inferior).

\section{Un ejemplo paradigmático de la Argentina que se moderniza. Los orígenes de “Tamet»}

Corría 1882 en Buenos Aires, funcionaban dos modestos talleres, Rezzonico y Otonello, uno como taller mecánico y de construcción de máquinas, y el segundo como fábrica de bulones, 20 años después Tomquist and $\mathrm{Co}$., la casa bancaria más antigua de la argentina, se asocia aportando los talleres «El Ancla» .En 1909 ampliadas las primeras actividades, se transforma en «Talleres Metalúrgicos» y con un capital de 1.300.000 pesos oro sellado, emitido e integrado totalmente por suscriptores argentinos.

En 1922, entra a formar parte de la entidad el grupo «Arbed-Terres Rouges», de Luxemburgo que representa a uno de los consorcios minero-metalúrgicos más importantes del mundo compuesto por distintas empresas industriales europeas y de ultramar, iniciador del cartel internacional del Acero. En América del Sud se destaca a «Tamet» en Argentina y en Brasil a la Companhia Siderúrgica Belgo Mineira»

La sociedad continuó acrecentando su importancia y en el año 1925, adquiere la mayor parte de los negocios de «Talleres San Martín Compañía Mercantil y Rural S.A.» tomando la denominación «S.A. Talleres Metalúrgicos San Martín». Posteriormente, una nueva adquisición, la de las fábricas y negocios de la ex-firma «Compañía argentina de Hierros y Aceros» (Pedro Vasena e hijos ltda.) fundada en 1870 , la convierte en la Empresa más importante de la América del Sud, en uno de los colosos industriales del país.

En los años posteriores, entre las representaciones ejercidas por Tamet, encontramos, aceros y herramientas producidas en Sheffield-Inglaterra; caños de fundición producidos en Nottingham, Inglaterra, rieles y tablestacas producidos en Luxemburgo; construcciones metálicas producidas en Bélgica; tambores metálicos producidos en Kolhn-Ehrenfeld.

Los productos elaborados por Tamet con marcas registradas, para construcciones metálicas, industriales, artículos de bulonería y afines, caños y accesorios de fundición, artículos de clavería, artefactos de calefacción, cocinas económicas a gas y supergas, artículos sanitarios de fundición esmaltada, bombas de pozo, braseros, ollas, cacerolas. Chapas galvanizadas, lisa y acanalada marca Bull-Dog, galpones económicos desmontables marca San Martín.

Los productos importados: Alambres de acero ovalado de alta resistencia «San Martín» o «Belgrano», «Sin Igual»; tablestacas metálicas «Belval» y «TerresRouges»; cañerías de obras de salubridad de «Stanton», para aceros y herramientas de «Arthur Balfour and Co. ldt.» de Shefield. Aceros de alta velocidad; super rápido; super extra rápido; mechas, fresas, hojas de sierra de acero para metales, acero inoxidable, de varios grados, en chapas y barra, en estado negro, decapado y pulido; alambres de acero; armazones patentados para hojas de sierras; limas, raspas, etc; polvo especial para cementaciones, etc.

Artefactos sanitarios de fundición esmaltada, común y antiácida, lavatorios, bañaderas, depósitos, separadores de grasa, palanganas, inodoros, mingitorios, rejillas, marcos bebederos, receptáculos, piletas para cocina, para lavar, baños de asiento ménsulas. Una amplia gama de artículos rurales y otros.

Se puede decir que esta empresa entre otras ha provisto gran parte de los componentes que la modernidad incorpora a los edificios. Pero no solo materiales sino que con ellos venían técnicas, modelos, nociones de aritmética, álgebra, geometría, cálculos, reducciones, equivalencias, fórmulas, normas, conversiones, modos de hacer, de montar, de terminar, a través de sus manuales técnicos.

Sin restar valores artísticos a lo construido y gozado por los usuarios en su tiempo, hoy podemos ver el discurso que fundaba aquella arquitectura, como de poco alcance, si la relacionamos con el legítimo propósito del hacer de los arquitectos, (armonizar el mundo material con la vida humana). Manual Técnico. Editado por TAMET. Sin lugar ni fecha. 
¿ Qué hubo detrás de esa expresión gráfica resultado del trabajo de hacer arquitectura? «...los primeros vagidos de la cultura nacional, sin fuerza propia y divorciada de su raigambre hispana por resentimientos de la independencia, eran ecos de la cultura francesa». contestaría Ciria y Sanguinetti. (3)

El mundo había cambiado radicalmente, desde que la guerra mundial marcó el fin de la belle époque, demostrando la crisis del nacionalismo exacerbado y de la ilusión de progreso gradual e indefinido. La ciencia inventaba prodigios: cine, teléfono, gramófono, radio, automóvil, aeroplano. El arte desquiciaba sus vetustos moldes, y proliferaba en agrios y polémicos «ismos».

\section{Elegimos, de aquellas, no tan al azar, una línea}

«la arquitectura sigue siendo el gran proceso sintético de combinación de miles de funciones humanas definidas y su propósito sigue consistiendo en armonizar el mundo mate-

(3) Ciria y Sanguinettti. Ob. Cit.

(5) Citado por Eduardo Sacriste. Cfr. Sacriste, Eduardo. Charlas para Principiantes. Buenos Aires..

(4) Molina y Vedia, Mario. Ob. Cit

(5) Citado por Molina Vedia.

(6) ¿Como es este mundo que se globaliza?

La cumbre mundial sobre Desarrollo Social, en Copenhague, Dinamarca -marzo/95- pone de relieve esta situación: Participaron más de noventa jefes de Estado, más de 2.000 grupos no gubernamentales. En este marco la observación más crítica sobre la realidad -entre otras- tal vez haya sido la rial con la vida humana». Alvar Aalto. (4)

Quizás Alvar Alto - entre otrosseñale aquí: Por una parte, a la arquitectura como resultado de un método de diseño (proceso sintético de combinación de miles de funciones humanas definidas) cuya lógica y coherencia tiene que ver con una aguda observación -mediante análisis- de la realidad de su tiempo, como lo era la creciente división social del trabajo como un nuevo modo de producción para la obtención de productos u obras a partir de la intervención de diversos trabajadores, este substancialmente distinto al modo de producción artesanal.

Por otra parte, establece el más elevado propósito para la arquitectura, nuestro artista y célebre maestro entre otros- otorga de este modo dirección, consistencia, integralidad y sustento a la práctica social de los arquitectos, «que en realidad focalizó solo en aquellas ciudades, para obras singulares y expresivas, que se conformaban sobre la base de los procesos de acumulación de capital».

\section{La especificidad}

«La Arquitectura - escribe Molina y Vedia-no puede por sí sola modificar toda la realidad circundante, debe contribuir a modificarla, debe colaborar en la mejora del habitat fisico y cultural» (5), aunque - escribe Bohigas- «está muy apartado de su cometido el cambiar radicalmente los procesos productivos, económicos y políticos más generales". (6) 


\section{El marco de trabajo de los arquitectos}

El trabajo de hacer arquitectura en la argentina se enmarca hoy, en la Vida Democrática que se reinstala en 1983 en procura de la libertad social, la que pretende liberar las energías materiales y morales de la sociedad. Se manifiestan nuevamente, aunque con lentitud, el talento, la iniciativa, el reencuentro político y social que conforma el ámbito necesario para utilizar nuestras capacidades de hacer en vista a la satisfacción de las necesidades públicas o colectivas en términos de mejoramiento de la calidad de vida.

A partir de 1989, la Argentina estructura sus rumbos políticos hacia la integración plena a un mundo que se globaliza, que se expresa, al decir de sus ejecutores en «la Transformación Nacional para el crecimiento, mediante un modo de relación social, más humano, más solidario, que rescate y edifique nuestra identidad moral y cultural».

Estos deseos cuyos hechos no carecen de las contradicciones propias del cambio social, constituyen hoy - nos guste o no-, el marco que reúne y anima a los argentinos y cuyas posibilidades de realizarse dependerán de que comprendamos sus finalidades; $y$ de nuestros esfuerzos para observar críticamente esta nueva construcción de la realidad que involucra y compromete al espacio en cuyas dimensiones (el desarrollo social, técnico y económico) opera creativamente el arquitecto, esto hace más necesario que nunca, el entender sobre el ser y hacer del/los arquitecto/s.

\section{Momento oportuno}

Creemos que este, es un momento oportuno para preguntarnos y tratar

del Programa de Naciones Unidas para el Medio Ambiente (PNUMA) que proclamó un compromiso para luchar contra la pobreza, fomentar la solidaridad y contribuir a la creación de empleo en todo el mundo.

El testimonio extenso de PNUMA, enfoca la crisis social contemporánea en el marco de una degradación ambiental donde resalta la deforestación, el descenso de la fauna ictícola, la contaminación y los desechos peligrosos. Destaca que «el $40 \%$ de la población del mundo está empobrecido, 1.100 millones de personas viven en la pobreza absoluta y cada día mueren 40.000 niños víctimas de la enfermedad y la desnutrición. * Agrega que «nuestro medio natural se deteriora, en cada segundo se liberan más de 200 toneladas de dióxido de carbono». "Cada día se destruyen 47.000 hectáreas de bosque, 346.000 has. de tierra se convierten en desierto y se extinguen entre 100 y 300 especies». Se indicó que «la pobreza y la degradación ambiental están estrechamente interrelacionadas, lo cual da lugar a un círculo vicioso, donde ambas se perpetúan en el mundo entero». (¿Serán los autos de los pobres que liberan tanto dióxido de carbono?).

Se criticó también las pautas de consumo del mundo industrializado y se dijo que «son insostenibles y ponen en peligro el equilibrio ecológico del planeta, lo cual acentúa las desigualdades sociales y la pobreza».

Escribe Michael Muller, miembro social demócrata del Parlamento Federal, de Alemania- «El modelo de crecimiento industrial traspuso ya hace mucho -en un mundo finito-, los límites de la desigualdad social y la compatibilidad ecológica.»

El mismo autor, refiriéndose a el compromiso asumido por 159 jefes de Estado en la Cumbre Mundial de 1922 escribe «Pese a que los peligros son conjurados de modo creciente en términos verbales, aún no se registra una verdadera comprensión profunda de las dimensiones y el alcance de la amenaza. Esa comprensión sería, sin embargo, la premisa para la substitución de las ideas mecanicistas de la pervertida modernidad técnica y económica, ideas que sostienen que todo es paliable gracias a la técnica y al orden económico.»

No eximimos de la responsabilidad moral de los estados industriales para reparar los efectos generados por el colonialismo, ya que solo ellos pueden iniciar un viraje sobre la base de su potencial económico, técnico y político. 
de entender, que es hacer arquitectura en el marco de la Transformación Nacional, cuyos presupuestos, la Reforma del Estado y la Revolución Productiva, si bien incipientes, contradictorios y dinámicos, contienen una fuerte voluntad social, cultural y política para su concreción.

\section{Agradecemos}

Estamos alentados por muchas personas cuyos puntos de vista se traducen en estas páginas, que esperamos sirvan como nuestro agradecimiento a ellas.

Un reconocimiento adecuado sería extender demasiado esta publicación porque fuimos muchos los arquitectos que durante años pensamos y experimentamos el hacer y el enseñar a hacer arquitectura.

\section{BUSCANDO DEFINICIONES}

Ninguna definición de Arquitectura, aún la de los maestros más celebres, mantiene totalmente su vigencia en el tiempo, ni satisface plenamente la necesidad de orientar permanentemente la práctica social de los arquitectos. Esto se debe a que ellas aparecen en los hechos (haciendo arquitectura) y son lanzadas en la mesa de nuestras discusiones en el marco de polémicas mayores, dadas en ciertos momentos de la historia cultural y así se constituyen en verdades transitorias, que al paso del tiempo inevitablemente van construyendo las grandes líneas de orientación que asume la práctica, y es esta misma la que permite visualizar su utilidad social, la que determina el hacer específico o su extinción como práctica profesional.

\section{La norma}

El arquitecto siempre ha actuado y debe actuar dentro de las grandes líneas de orientación, pero con ajuste a los marcos concretos que constituyen las acciones sociales de las que forma parte inseparable.

\section{Su atención... Por favor}

Cuando Ud., lector preocupado por la arquitectura, ha viajado por doquier conociendo ciudades, contemplando muchos edificios, incluso visitando las obras más recientes, (kitsch, revivals historicistas, tendencia, posmodernismo, etc.), no va a aceptar tan fácilmente lo que le vamos a proponer, porque por costumbre miramos sin ver, esto mismo debiera servir para que nos preste la atención necesaria para reflexionar y luego juntos, podamos multiplicar y enriquecer nuestras específicas actividades.

\section{Intentamos}

...una nueva definición acorde a los tiempos que vivimos, interpretar lo que hacemos, y ver lo que debemos hacer en este proceso las personas que trabajamos y que la sociedad identifica no sin dificultad como arquitectos. 


\section{Entre otros, lo que hacen los arquitectos}

A los efectos de una reflexión.

Pocos colegas consiguen con facilidad insertarse laboralmente (7), muchos y cada vez más, no lo pueden hacer, porque en su mayoría cuando alumnos de las facultades de arquitectura, sólo receptaron el modelo educativo que lleva a la extinción de la práctica profesional.

Al mismo tiempo la corporación de arquitectos con su conducta institucional, -que ha sido invariable desde su creación - para con la sociedad, ha contribuido eficazmente a ello, toda vez que ha esgrimido argumentos cada vez más débiles para subsistir con la organización frente a los legitimas embates políticos y sociales.

Nos referimos al modelo educativo que hace, que tanto la arquitectura y el urbanismo, como el diseño de objetos sean considerados cada vez más, como un campo proyectual de formalización ideal, sin contenido, donde - casi podríamos decir de muchos trabajos-, son caricaturescos del primer mundo, publicitarios, en tanto alejados totalmente de la realidad económico-social/ territorial- la que pasa desapercibida o negada casi totalmente. Si bien existen excepciones, aún son insuficientes.

El rediseño del subsistema ambiental físico-simbólico del habitat en general, por medio de esa vía de exclusividad formalista ha puesto en duda la utilidad social de la labor de los arquitectos, por cuanto el produc- to de ese trabajo, la sociedad en general, ya no demanda, a no ser a partir de la obligatoriedad municipal de presentar documentación técnica con la firma de un matriculado.

Fernández Alba, dice desde el Diseño del Habitat y los nuevos factores económicos y sociales: "Muchas de estas actitudes como sabemos, se deben en parte a un desconocimiento por parte de los operadores de la forma (diseñadores, arquitectos, urbanistas), del avance de las ciencias sociales y del factor determinante que significan los factores económicos, lagunas que inciden en fomentar un desenfoque cultural con respecto al diseño, derivando las formulaciones teórico-prácticas del proyecto, en el caso de la arquitectura es evidente. hacia disquisiciones de una componente básicamente irracional, según la cual se enfatizan las formas sin atender a los contenidos que las determinan». (8)

El fenómeno de posmodernidad, como dice Norberto Chávez en diálogo con Clarín (9), es en general: «un festejo cínico del fracaso de la razón y según ese cinismo sea crítico-pocas veces lo es-o sea lúdico estare-

(7) Es decir, instalar el estudio, y obtener la totalidad de sus ingresos de los clientes que todos los días le solicitan obras de arquitectura.

(8) Fernández Alba, Antonio. El diseño del habitat y los nuevos factores económicos y sociales. en Martín Mateo, Ramón. La ciudad filoenergética. Editado por el Instituto de estudios de Administración Local. Madrid. 1981.

(9) Diario «Clarín». Buenos Aires. 19 de agosto de 1988. 
mos en las dos grandes vertientes de la producción arquitectónica contemporánea», que irradian los lugares centrales.

\section{Definimos... Entre otros a los arquitectos}

Como las personas a quienes la sociedad les ha delegado, la gran responsabilidad de operar, en la viabilidad del subsistema ambiental de sustentación físico-simbólico para el desarrollo de su vida en el Habitat, que hacen, sobre la base de evaluaciones, el rediseño de las actividades, organizan y/o conducen el trabajo social necesario, tecnológicamente estructurado, de y en determinadas acciones sociales productoras de relaciones y flujos de ideas, objetos y procesos en el espacio, que son las que materializan el contexto, que les sirve de soporte histórico y que modifican sucesivamente cuando hace crisis.

El ensayo de la definición precedente, resulta de una profunda reflexión sobre la preocupación existencial que se manifiesta de diversas formas en el hacer cotidiano de los arquitectos, y la misma contiene en forma implícita, opciones para diversas vías de actuación profesional.

Decimos que la sociedad nos ha delegado la responsabilidad de operar, en términos de deber personal y comunitario. Esto nos pone frente al espejo para preguntarnos con total franqueza sobre nuestra ética y moral solidaria. Sobre nuestra actitud crítica, sobre nuestra aptitud técnica, so- bre nuestra capacidad para resolver problemas sentidos por la comunidad. Sobre nuestra inserción corporativa. Sobre la visión sistémica e integradora.

Decimos operar en la viabilidad del subsistema ambiental en términos de accesibilidad al mejoramiento, uso y goce de la calidad ambiental, de los procesos participativos, de los objetos imprescindibles para la vida, de y para todos, sin desmejorar la calidad de vida de nadie.

Decimos rediseño, sobre la base de evaluaciones, porque siempre, adoptamos o tomamos como base una solución anterior ya sea que la misma -en el peor de los casos- se halle todavía en el papel, como una hipótesis no comprobada, lo que nos lleva casi inevitablemente a una no deseada utopía por su desenfoque cultural y a quedarnos sin trabajo, o en el mejor de los casos verificada, es decir construida, usufructuada y/o gozada por la gente.

Decimos organizar el trabajo y/o la conducción de las actividades, cuando nos referimos a la tarea de previsión para poder llevar adelante la obra en toda su complejidad, y especialmente la de coordinar bajo consenso a todas las personas que intencional y tecnológicamente hayamos estructurado en el proyecto para concretar la construcción, el uso y el goce de la obra.

El rediseño y la conducción del trabajo social necesario, de y en ciertos colectivos sociales, debe ser cuidadosamente pensado y realizado, porque en ello radica la viabilidad del 
arquitecto, su desafío cotidiano, el meritorio reconocimiento social de su actividad y que consiste en la aplicación de su esfuerzo creativo intelectual y físico en la optimización de la tecnología social o sea de los medios y procedimientos que la sociedad utiliza para resolver aquellos asuntos que la misma, en su oportunidad, identifica o entiende como problema, el desajuste, la disfuncionalidad o la carencia de algo relativo a la eficacia y eficiencia de la producción social ambiental, física - simbólica.

Entendemos por eficacia, a la medida con que la población satisface sus necesidades y por eficiencia, a la productividad con que la sociedad utiliza los recursos existentes.

Cuando decimos el rediseño del trabajo de y en ciertos colectivos sociales, nos referimos a la actividad de muchas y determinadas personas, como señala el arquitecto Jorge Togneri (10) «aunque tal vez ellas a menudo ignoren que su parte, colocar un ladrillo, trazar una línea, comprar cemento, conducir un camión con arena, está intimamente vinculada con otras, personas físicas o jurídicas», ... «que son variadas y numerosas» ... "conforma así una estructura, ninguna de cuyas partes puede ser eliminada, sin que se altere la totalidad».

Esto es fácil de observar si analizamos desde este punto de vista, el manual del Arq. Jaime Nisnovich (11), producto de su träbajo de recopilación y ordenamiento del cómo se hace, mediante el conocimiento de las estrategias alternativas de nivel popular, proceso este que le dio evidencias sobre el cómo se programa, diseña y construye, con las técnicas y materiales más utilizados por los autoconstructores y luego rediseña ese trabajo social, mejorando los modos de hacer y lo difunde después como manual mediante el cual comunica el cómo hacerlo mejor, a través de técnicas gráficas, representando a el producto, sea un elemento constructivo simple, o semiterminado y/o terminado con sus respectivos insumos de materias primas, materiales, máquinas, equipos, herramientas y mediante escritos da las técnicas que guían las operaciones del trabajo de la gente, o sea que produce la prefiguración conceptual de los trabajos sociales necesarios, (lo que llamamos propuesta tecnológica), para la obtención - mediante el trabajo - de elementos o partes del todo, de lo que va a ser lo ambiental de sustentación físico-simbólico una vez construido y usufructuado.

Además utiliza técnicas escritas para explicar lo que va a ser y/o implicar, la dinámica propia de cada paso en el proceso productivo que deberá asumir la gente para obtener el producto material de ese trabajo rediseñado, dirigidas a quienes, los que

(10) Togneri, Jorge. Polémica en la Arquitectura. Buenos Aires. Espacio Editora S.A. 1984.

(11) Nisnovich, Jaime. Manual del autoconstructor. Buenos Aires. Club de Autoconstructores El Hornero. 1988. 
con diversos tipos y grados de poder, organización, participación y que por negociaciones y consenso, están por empezar a construir su propia casa, a quienes la quieren continuar, ampliar o terminar, a quienes pueden asesorar a sus vecinos, a miembros de organizaciones barriales preocupadas por el entorno, y a toda persona preocupada en la resolución de problemas que identifica como propios y que para su solución debe llevar adelante ciertos trabajos. A esto llamamos medios y procedimientos, o tecnología social o simplemente trabajo.

Similar, sería lo que hacemos cotidianamente dirigido al sector «de la construcción» tanto para el que se encuentra formalmente estructurado como el que no, el informal.

El concepto de trabajo que estamos manejando es abarcativo y se refiere a las diversas acciones sociales, cualquiera de las formas que adopta la sociedad, (actores sociales) sean enti-

(12) Una crisis revelada -entre otras ya señaladas- por indicadores, es la situación de desempleo y el peso de la población con necesidades básicas insatisfechas (N.B.I), que lleva a los actores preocupados a considerar el rol de la economía en el Nordeste Argentino, en el contexto nacional y en el Mercosur, a establecer políticas y estrategias como la promoción del empleo y la reconversión laboral, a repensar el rol de instituciones educativas públicas y priyadas, y a poner en valor a los recursos humanos necesarios para la transformación.

Un proceso de Reforma Estatal, consensuado por partidos políticos mayoritarios, que se concreta no sin obstáculos en la descentralización institucional con escasos recursos, lo que dificulta la prestación de los servicios públicos, la ausencia de la planificación regional y del planeamiento urbano, la ineficacia de la política habitacional, que lleva a los actores a la necesidad de plantearse los conflictos y alternativas, el rol de los Municipios y las municipalidades. dades económico-coorporativas, como la C.A.C., que agrupa a los empresarios de la construcción; las sociales, como comisiones vecinales, etc.; las políticas, como las unidades básicas o comités y las estatales en sus distintos niveles y competencias.

\section{UNA CONVOCATORIA}

El trabajo específico de hacer arquitectura, el que debe distinguir $\mathbf{y}$ caracterizar hoy al arquitecto, debe decir presente en nuestra región, donde se ha ampliado el espacio económica (Mercosur), las acciones sociales se desenvuelven en el marco de una crisis socio-económica (12), que se refleja en el aspecto ambiental físico-simbólico de las ciudades, donde la casi nula participación de los arquitectos, revela el déficit en la organización y dirección de los mismos y en el modelo educativo implementado en la Facultad de Arquitectura y Urbanismo, de una Universidad Nacional del Nordeste, cuya existencia se debe a legítimos propósitos enunciados en su fundación, y que debieran ser hoy los desafíos a asumir por la comunidad universitaria, donde se produce la formación de arquitectos, a partir de sus centros de estudiantes, cátedras, áreas de ciencias, departamentos, institutos, etc, sin más demoras.

\section{Mientras tanto}

La crisis en la formación de los ar- 
quitectos, las incertidumbres que conlleva el trabajo profesional y otras circunstancias, configuran una recurrente y nueva situación difícil para el desarrollo social y al mismo tiempo un desafío a la creatividad de los arquitectos del pueblo de la Nación.

Desde su propio horizonte, un pueblo cualquiera sea su localización, extensión y densidad de población, aún con individuos o grupos socialmente heterogéneos, en diversos grados, se congrega e integra y trabaja, organiza, proyecta desde sí, y trabaja una y otra vez, y es mediante estas acciones sociales como realiza su historia y es en ese horizonte cultural crítico, donde aparece socialmente reconocido y actúa el arquitecto con diversos grados de conciencia, y siempre desde posiciones culturales, ideológicas y éticas comprometidas con la sociedad donde viven o a la cual sirven.

Un horizonte cultural lleno de problemas y contradicciones, sucesivas crisis, nuevas o recurrentes, constituyen el germen de la esperanza de los pueblos, por ello las combaten, las vencen y las superan, cada pueblo según sus posibilidades-recursos, se toma con calma, con sus tiempos y casi con resignación su inevitable tarea histórica, la de abordar la misma con proyectos propios, creativos y novedosos.
La incertidumbre del futuro se achica, si a corto plazo, contamos con profesionales ingeniosos, capaces de rediseñar con eficacia y eficiencia el trabajo social necesario para la producción material armónica con la vida de la gente.

\section{LA PREOCUPACIÓN EXISTENGIAL}

La preocupación existencial de los arquitectos se manifiesta en términos de ser o no ser socialmente útiles y necesarios en el proceso de transformación nacional en el marco de la vida democrática reinstalada en el país desde 1983. Ya han pasado 11 años y la situación de los arquitectos - según muchos especialistas que producen análisis derivados de la hegemonía del centralismo autoritario e irreflexivo - tiende a agravarse.

Los más optimistas, -nos incluimos - opinamos que este proceso está abriendo infinitas vetas a explorar de actuación profeșional. Dependiendo ello, de una elección, de una cierta forma de situarnos, ya sea con el mejor nivel técnico-científico totalmente enlazado con el pueblo o sirviendo, - desde una cultura de importación-, a una elite decadente, de algunos pocos sectores sociales privilegiados. 